\title{
Haloterrigena jeotgali sp. nov., an extremely halophilic archaeon from salt-fermented food
}

Correspondence

Jin-Woo Bae

baejw@khu.ac.kr

\author{
Seong Woon Roh, ${ }^{1,2}$ Young-Do Nam, ${ }^{1,2}$ Ho-Won Chang, ${ }^{2}$ \\ Kyoung-Ho Kim, ${ }^{1}$ Youlboong Sung, ${ }^{2}$ Min-Soo Kim, ${ }^{1,2}$ Hee-Mock Oh ${ }^{2}$ \\ and Jin-Woo Bae ${ }^{1,2}$ \\ ${ }^{1}$ Department of Life and Nanopharmaceutical Sciences, and Department of Biology, Kyung Hee \\ University, Seoul 130-701, Republic of Korea \\ ${ }^{2}$ University of Science \& Technology, Biological Resource Center, KRIBB, Daejeon 305-806, \\ Republic of Korea
}

Although high salinity is toxic to most cells, extreme halophiles are well adapted to their hypersaline environment (Grant, 2004). Since the establishment of the genus Haloterrigena within the family Halobacteriaceae in 1999 (Ventosa et al., 1999), at the time of writing seven species belonging to it have been described: Haloterrigena turkmenica (Ventosa et al., 1999), Haloterrigena thermotolerans (Montalvo-Rodríguez et al., 2000), Haloterrigena saccharevitans (Xu et al., 2005a), Haloterrigena longa and Haloterrigena limicola (Cui et al., 2006), Haloterrigena hispanica (Romano et al., 2007) and Haloterrigena salina (Gutiérrez et al., 2008). To further increase our understanding of the family Halobacteriaceae, we searched for novel strains of this family in shrimp jeotgal, a traditional fermented seafood from Korea that comprises small

Abbreviations: S-DGD, mannose-6-sulfate(1-2)-glucose glycerol diether; $S_{2}-D G D$, mannose-2,6-disulfate(1-2)-glucose glycerol diether.

The GenBank/EMBL/DDBJ accession number for the 16S rRNA gene sequence of strain $A 29^{\top}$ is EF077633.

Phylogenetic trees based on 16S rRNA gene sequences generated by the minimum-evolution and maximum-parsimony methods, and a thinlayer chromatogram of the polar lipids of strain $\mathrm{A} 29^{\top}$ and a reference strain $\left(H\right.$. thermotolerans $\left.P R 5^{\top}\right)$ are available as supplementary figures in IJSEM Online. shrimps and rock salt. Shrimp jeotgal has a liquid component with a salt concentration close to or at saturation (approx. 35\%,w/v), and it is known to be a reservoir of halophilic bacteria, such as Jeotgalicoccus halotolerans (Yoon et al., 2003b), Salinicoccus jeotgali (Aslam et al., 2007b), Bacillus jeotgali (Yoon et al., 2001), Nesterenkonia jeotgali (Yoon et al., 2006), Methylobacterium jeotgali (Aslam et al., 2007a) and Psychrobacter jeotgali (Yoon et al., 2003a), and halophilic archaea such as Natronococcus jeotgali (Roh et al., 2007a) and Halalkalicoccus jeotgali (Roh et al., 2007b). A novel strain, designated $\mathrm{A} 29^{\mathrm{T}}$, was isolated from shrimp jeotgal on a medium designed for halophilic archaea. On the basis of $16 \mathrm{~S}$ rRNA gene sequence analysis, strain $\mathrm{A} 29^{\mathrm{T}}$ was determined to belong to the genus Haloterrigena. In this paper, we describe the taxonomic position of this strain through phenotypic, genotypic and chemotaxonomic analyses.

Strain $\mathrm{A} 29^{\mathrm{T}}$ was isolated on a complex medium (DSM medium 954) containing $\left(\mathrm{g} \mathrm{l}^{-1}\right)$ Casamino acids (5; Difco), yeast extract (5; Difco), $\mathrm{MgCl}_{2} \cdot 6 \mathrm{H}_{2} \mathrm{O}$ (20), $\mathrm{KCl}$ (2), Tris (12), $\mathrm{CaCl}_{2} \cdot 2 \mathrm{H}_{2} \mathrm{O}(0.2)$ and $\mathrm{NaCl}(200)$ in the presence of antimicrobial compounds (penicillin $\mathrm{G}$, erythromycin and cycloheximide, $100 \mu \mathrm{g} \mathrm{ml}^{-1}$ ) that are known to inhibit bacteria and eukaryotes but not archaea (Purdy et al., 
2004). The $\mathrm{pH}$ was adjusted to 7.5 and incubation was at $37{ }^{\circ} \mathrm{C}$ for approximately 7 days. A pure culture was obtained by repeated restreaking. Phenotypic tests were performed in accordance with the proposed minimal standards for the description of new taxa in the order Halobacteriales (Oren et al., 1997). Cell morphology was examined using light (Eclipse 80i; Nikon) and electron microscopy (JEM 1010; JEOL). Gram staining was performed as described by Dussault (1955) and motility was examined on semi-solid agar. Optimal conditions for growth were determined in medium 954 containing 0 $30 \%(\mathrm{w} / \mathrm{v}) \mathrm{NaCl}$, and the $\mathrm{pH}$ range for growth was assayed from $\mathrm{pH} 5.0$ to 11.0 at intervals of 0.5 , and at different temperatures $(4,10,15,17,21,25,30,37,45,50$ and $\left.60{ }^{\circ} \mathrm{C}\right)$. The $\mathrm{Mg}^{2+}$ requirement for growth was also determined using medium 954 without $\mathrm{MgCl}_{2} \cdot 6 \mathrm{H}_{2} \mathrm{O}$ and yeast extract. Standard phenotypic tests for indole formation, nitrate reduction, hydrolysis of casein, starch and urea, and activity of oxidase and catalase were conducted as described by Gerhardt et al. (1994). Hydrolysis of gelatin and Tween 80 were tested simultaneously through the procedure adapted for haloarchaea by Gutiérrez \& González (1972). Cell lysis in distilled water was detected by microscopic examination. DNase activity was detected on $\mathrm{T}-\mathrm{Hv}$ agar medium as described by González et al. (1978). Utilization of sole carbon and energy sources, and acid production from sugars were determined as described by Montalvo-Rodríguez et al. (2000). Anaerobic growth in the presence of nitrate, sulfate, thiosulfate, DMSO and TMAO was tested in filled, stoppered tubes with Sehgal-Gibbons (SG) medium (Sehgal \& Gibbons, 1960) for 1 month.

The isolate is Gram-negative and non-motile. This strain grows in the ranges $10-30 \% \mathrm{NaCl}, 17-50{ }^{\circ} \mathrm{C}$ and $\mathrm{pH} 6.5-$
8.5 , with optimal growth occurring at $15-20 \% \mathrm{NaCl}, 37-$ $45{ }^{\circ} \mathrm{C}$ and $\mathrm{pH}$ 7.0-7.5. Phenotypic differences between strain $\mathrm{A} 29^{\mathrm{T}}$ and type strains of other species of the genus are shown in Table 1. As shown in Table 1, the new isolate can be differentiated from other closely related species by several phenotypic properties.

Chromosomal DNA was extracted and purified as described by Sambrook et al. (1989). The 16S rRNA gene was amplified by PCR using PCR Pre-Mix (iNtRON Biotechnology) and two universal primers, as described by Baker et al. (2003). Sequencing of the amplified 16S rRNA gene and phylogenetic analysis were performed as described previously (Roh et al., 2008). Phylogenetic relationships between closely related species were determined using MEGA4 (Tamura et al., 2007) and used to elaborate dendrograms by the neighbour-joining (Saitou \& Nei, 1987), minimum-evolution (Rzhetsky \& Nei, 1992) and maximum-parsimony (Kluge \& Farris, 1969) methods. A bootstrap analysis investigating the stability of the trees was performed by obtaining a consensus tree based on 1000 randomly generated trees. Strain $\mathrm{A} 29^{\mathrm{T}}$ showed the highest level of 16S rRNA gene similarity to $H$. thermotolerans $\mathrm{PR}^{\mathrm{T}}$ (99.0\%), H. saccharevitans $\mathrm{AB} 14^{\mathrm{T}}(98.3 \%)$, H. limicola $\mathrm{AX}-7^{\mathrm{T}}(97.1 \%)$, H. turkmenica $4 \mathrm{k}^{\mathrm{T}}(96.4 \%)$, H. salina XH-65 $5^{\mathrm{T}}(96.3 \%)$, H. hispanica $\mathrm{FP}^{\mathrm{T}}(96.1 \%)$ and H. longa $\mathrm{ABH} 32^{\mathrm{T}}$ (94.8\%). Phylogenetic trees based on $16 \mathrm{~S}$ rRNA gene sequences indicated that the genus Haloterrigena can be divided into four groups, strain A $29^{\mathrm{T}}$ forming a separate clade with $H$. thermotolerans and $H$. saccharevitans, adjacent to the genus Natrinema, regardless of tree-making algorithms used, with high bootstrap values of 98,99 and 92 based on the neighbour-joining, minimum-evolution and maximumparsimony methods, respectively (Fig. 1; Supplementary

Table 1. Characteristics that differentiate H. jeotgali sp. nov. from its closest phylogenetic relatives

Species: 1, H. jeotgali sp. nov.; 2, H. limicola (data from Cui et al., 2006); 3, H. longa (Cui et al., 2006); 4, H. saccharevitans (Xu et al., 2005a); 5, H. thermotolerans (Montalvo-Rodríguez et al., 2000); 6, H. turkmenica (Ventosa et al., 1999); 7, H. hispanica (Romano et al., 2007); 8, H. salina (Gutiérrez et al., 2008). +, Positive; -, negative; NR, not reported.

\begin{tabular}{|c|c|c|c|c|c|c|c|c|}
\hline Characteristic & 1 & 2 & 3 & 4 & 5 & 6 & 7 & 8 \\
\hline Cell morphology & Rods & Rods & Rods & Rods/coccoid & Rods & Coccoid & Coccoid & Coccoid \\
\hline Motility & - & + & - & + & - & - & - & - \\
\hline Growth at $20{ }^{\circ} \mathrm{C}$ & + & - & - & - & - & NR & - & - \\
\hline Nitrate reduction & - & + & - & + & + & - & + & - \\
\hline $\mathrm{Mg}^{2+}$ requirement & - & + & - & - & - & + & - & - \\
\hline Indole formation & + & - & + & - & - & - & + & - \\
\hline Oxidase & - & + & + & + & + & NR & + & + \\
\hline \multicolumn{9}{|l|}{ Utilization of: } \\
\hline Glucose & - & - & + & - & - & + & - & + \\
\hline Sucrose & - & - & + & - & - & + & - & - \\
\hline Fructose & + & - & - & - & - & + & - & + \\
\hline Presence of S-DGD & - & - & - & - & - & - & + & - \\
\hline Presence of $S_{2}$-DGD & + & + & + & + & + & + & - & + \\
\hline $\mathrm{G}+\mathrm{C}$ content $(\mathrm{mol} \%)$ & 62.3 & 61.9 & 63.2 & 66.6 & 63.3 & 59.8 & 62.0 & 67.0 \\
\hline
\end{tabular}


Fig. S1, available in IJSEM Online). DNA-DNA hybridization was performed by using the fluorometric method of Ezaki et al. (1989). The DNA-DNA relatedness between strain $\mathrm{A} 29^{\mathrm{T}}$ and the related strains $H$. thermotolerans $\mathrm{PR} 5^{\mathrm{T}}$, H. saccharevitans $\mathrm{AB} 14^{\mathrm{T}}$ and $H$. limicola $\mathrm{AX}-7^{\mathrm{T}}$ is $23.2,22.0$ and $17.9 \%$, respectively. The $16 \mathrm{~S}$ rRNA gene sequence similarity data and a DNA-DNA relatedness value of less than $70 \%$ (Wayne et al., 1987) indicate that strain $\mathrm{A} 29^{\mathrm{T}}$ could be a distinct genospecies.

The $\mathrm{G}+\mathrm{C}$ content was determined by a fluorimetric method using SYBR Green and a real-time PCR thermocycler (González \& Saiz-Jimenez, 2002). The G +C content of genomic DNA of strain $\mathrm{A} 29^{\mathrm{T}}$ is $62.3 \mathrm{~mol} \%$, which is in the range of those of the validly published species of the genus Haloterrigena. Total lipids were extracted by the modified method of Xin et al. (2000), separated by one-dimensional thin-layer chromatogram on a Merck silica gel 60 F254 aluminium-backed plate with the solvent chloroform/ methanol/acetic acid/water $(85: 22.5: 10: 4$, by vol.), and detected by spraying the plate with specific reagents, as described by Tindall (1990). The designation of all spots was compared with reference strain $H$. thermotolerans $\mathrm{PR}^{\mathrm{T}}$. The polar lipid fraction contains phosphatidylglyerol (PG), phosphatidylglycerol phosphate methyl ester (PGP-Me), and mannose-2,6-disulfate(1-2)-glucose glycerol diether $\left(\mathrm{S}_{2}\right.$-DGD) (Supplementary Fig. S2, available in IJSEM Online). The polar lipid profile of strain $\mathrm{A} 29^{\mathrm{T}}$ resembles that of Haloterrigena species, containing PG, DPG-Me and $\mathrm{S}_{2}$-DGD (Cui et al., 2006; Gutiérrez et al., 2008; MontalvoRodríguez et al., 2000; Ventosa et al., 1999; Xu et al., 2005a).

It is known that the genera Haloterrigena and Natrinema overlap phylogenetically to some extent, and detailed taxonomic reassessment studies have been carried out (Montalvo-Rodríguez et al., 2000; Oren \& Ventosa, 2002). Currently, it is reported that Haloterrigena species contain the glycolipids $\mathrm{S}_{2}$-DGD (Cui et al., 2006; Gutiérrez et al., 2008; Montalvo-Rodríguez et al., 2000; Ventosa et al., 1999; $\mathrm{Xu}$ et al., 2005a) or mannose-6-sulfate(1-2)-glucose glycerol diether (S-DGD) (Romano et al., 2007), whereas most Natrinema species have phosphatidylglycerol sulfate (PGS) and unidentified glycolipids (McGenity et al., 1998; Tapingkae et al., 2008; Xin et al., 2000; Xu et al., 2005b). Even though strain $A 29^{\mathrm{T}}$ is phylogenetically related to members of both Haloterrigena and Natrinema, it is reasonable that strain $\mathrm{A} 29^{\mathrm{T}}$ can be classified as a member of the genus Haloterrigena based on the presence of $\mathrm{S}_{2}$ DGD, the fact that it clusters with members of the genus Haloterrigena in phylogenetic trees, and the fact that the highest 16S rRNA gene sequence similarities are shared with members of the genus Haloterrigena.

Results from 16S rRNA gene sequence analysis and chemotaxonomic, physiological and biochemical tests have identified genotypic and phenotypic differences between strain $\mathrm{A} 29^{\mathrm{T}}$ and other species in the genus Haloterrigena. Taken together, these data clearly differentiate the new isolate from other Haloterrigena species. Thus, on the basis of genetic, chemotaxonomic and phenotypic comparisons to previously described taxa, strain $\mathrm{A} 29^{\mathrm{T}}$ constitutes a novel species of the genus Haloterrigena, for which the name Haloterrigena jeotgali sp. nov. is proposed.

\section{Description of Haloterrigena jeotgali sp. nov.}

Haloterrigena jeotgali (je.ot.ga'li. N.L. gen. n. jeotgali of jeotgal, a traditional Korean fermented seafood).

Cells are Gram-negative, non-motile, rod-shaped $(0.4 \mu \mathrm{m}$ wide, $1.0 \mu \mathrm{m}$ long) and occur in irregular clusters. The colonies on complex agar medium are light red, circular and measure $0.5 \mathrm{~mm}$ in diameter after 7 days at $37{ }^{\circ} \mathrm{C}$. Growth occurs in the presence of $10-30 \%(w / v) ~ N a C l$ at

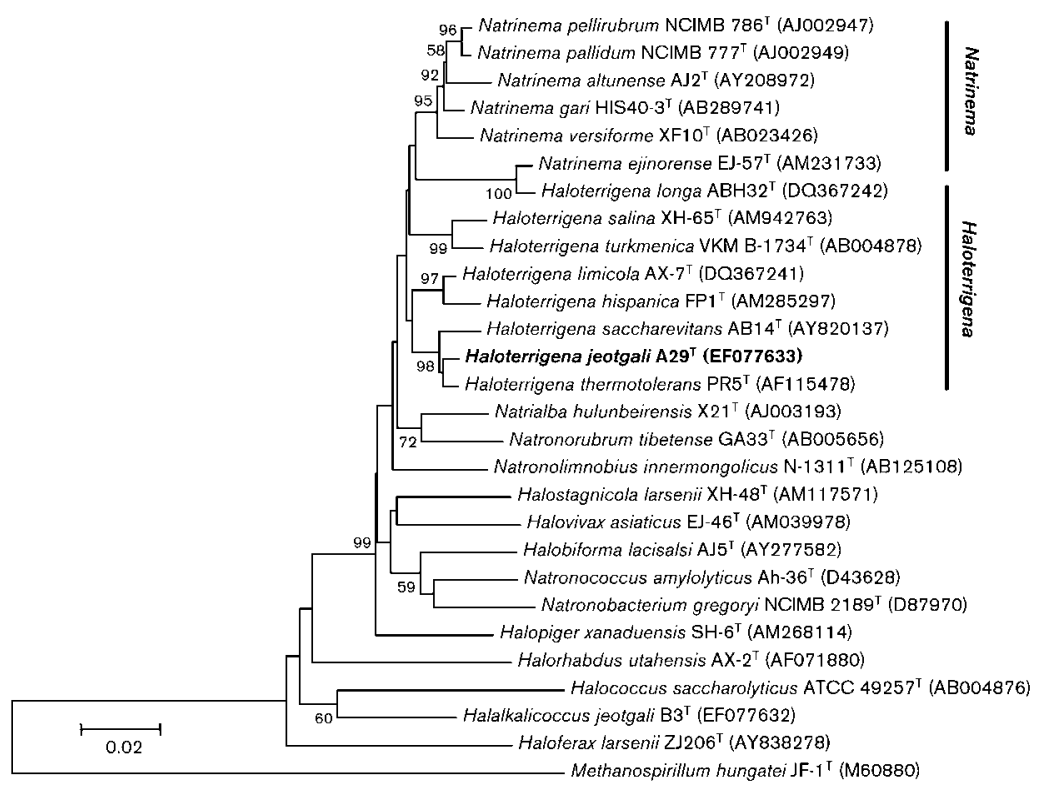

http://ijs.sgmjournals.org
Fig. 1. Phylogenetic tree, based on $16 \mathrm{~S}$ rRNA gene sequences, showing the position of strain $A 29^{\top}$ with respect to other species in the genus Haloterrigena, Natrinema and other haloarchaea. The tree was generated by the neighbour-joining method. The numbers at the nodes indicate bootstrap values (1000 replications). Bar, 0.02 accumulated changes per nucleotide. 
temperatures ranging from 17 to $50{ }^{\circ} \mathrm{C}$ and in the $\mathrm{pH}$ range 6.5-8.5. Optimal conditions are an $\mathrm{NaCl}$ concentration of $15-20 \%$, temperatures ranging from 37 to $45{ }^{\circ} \mathrm{C}$ and a $\mathrm{pH}$ of 7.0-7.5. The isolate is catalase-positive, oxidase-negative and does not reduce nitrate to nitrite. $\mathrm{Mg}^{2+}$ is not required for growth. Cell lysis occurs in distilled water. Casein and Tween 80 are hydrolysed, but starch, gelatin, urea and DNA are not. Positive for indole formation. Anaerobic growth with nitrate occurs, but not with sulfate, thiosulfate, DMSO and TMAO. Fructose, lactose and acetate are utilized as carbon and energy sources, but sucrose, glucose, citrate and formate are not. Acid is not produced from fructose, lactose, acetate, sucrose, glucose, citrate or formate. The polar lipid fraction consists of PG, PGP-Me and $\mathrm{S}_{2}$-DGD. Resistant to the following antimicrobial compounds $\left(\mu \mathrm{g} \mathrm{ml}^{-1}\right)$ : bacitracin (50), penicillin (50), ampicillin (50), chloramphenicol (50) and erythromycin (50). Sensitive to the following antimicrobial compounds $\left(\mu \mathrm{g} \mathrm{ml}^{-1}\right)$ : novobiocin (25), anisomycin (25) and aphidicolin (25). G + C content of genomic DNA of the type strain is $62.3 \mathrm{~mol} \%$.

The type strain is $\mathrm{A}_{2} 9^{\mathrm{T}} \quad\left(=\mathrm{KCTC} \quad 4020^{\mathrm{T}}=\mathrm{DSM}\right.$ $18794^{\mathrm{T}}=\mathrm{JCM} 14585^{\mathrm{T}}=$ CECT $\left.7218^{\mathrm{T}}\right)$ and it was isolated from shrimp jeotgal, a traditional Korean fermented food.

\section{Acknowledgements}

We thank Dr J. P. Euzéby (Ecole Nationale Vétérinaire, France) for etymological advice. This work was supported by NMC0300938, the Environmental Biotechnology National Core Research Center (KOSEF: R15-2003-012-02002-0) and TDPAF (Technology Development Program for Agriculture and Forestry).

\section{References}

Aslam, Z., Lee, C. S., Kim, K. H., Im, W. T., Ten, L. N. \& Lee, S. T. (2007a). Methylobacterium jeotgali sp. nov., a non-pigmented, facultatively methylotrophic bacterium isolated from jeotgal, a traditional Korean fermented seafood. Int J Syst Evol Microbiol 57, 566-571.

Aslam, Z., Lim, J. H., Im, W. T., Yasir, M., Chung, Y. R. \& Lee, S. T. (2007b). Salinicoccus jeotgali sp. nov., isolated from jeotgal, a traditional Korean fermented seafood. Int J Syst Evol Microbiol 57, 633-638.

Baker, G. C., Smith, J. J. \& Cowan, D. A. (2003). Review and reanalysis of domain-specific 16 S primers. J Microbiol Methods 55, 541555.

Cui, H. L., Tohty, D., Zhou, P. J. \& Liu, S. J. (2006). Haloterrigena longa sp. nov. and Haloterrigena limicola sp. nov., extremely halophilic archaea isolated from a salt lake. Int J Syst Evol Microbiol 56, 18371840.

Dussault, H. P. (1955). An improved technique for staining red halophilic bacteria. J Bacteriol 70, 484-485.

Ezaki, T., Hashimoto, Y. \& Yabuuchi, E. (1989). Fluorometric deoxyribonucleic acid-deoxyribonucleic acid hybridization in microdilution wells as an alternative to membrane filter hybridization in which radioisotopes are used to determine genetic relatedness among bacterial strains. Int J Syst Bacteriol 39, 224-229.
Gerhardt, P., Murray, R. G. E., Wood, W. A. \& Krieg, N. R. (editors) (1994). Methods for General and Molecular Bacteriology. Washington, DC: American Society for Microbiology.

González, J. M. \& Saiz-Jimenez, C. (2002). A fluorimetric method for the estimation of $\mathrm{G}+\mathrm{C}$ mol\% content in microorganisms by thermal denaturation temperature. Environ Microbiol 4, 770-773.

González, C., Gutiérrez, C. \& Ramirez, C. (1978). Halobacterium vallismortis sp. nov. An amylolytic and carbohydrate-metabolizing, extremely halophilic bacterium. Can J Microbiol 24, 710-715.

Grant, W. D. (2004). Life at low water activity. Philos Trans R Soc Lond B Biol Sci 359, 1249-1267.

Gutiérrez, C. \& González, C. (1972). Method for simultaneous detection of proteinase and esterase activities in extremely halophilic bacteria. Appl Microbiol 24, 516-517.

Gutiérrez, M. C., Castillo, A. M., Kamekura, M. \& Ventosa, A. (2008). Haloterrigena salina sp. nov., an extremely halophilic archaeon isolated from a salt lake. Int J Syst Evol Microbiol 58, 2880-2884.

Kluge, A. G. \& Farris, J. S. (1969). Quantitative phyletics and the evolution of anurans. Syst Zool 18, 1-32.

McGenity, T. J., Gemmell, R. T. \& Grant, W. D. (1998). Proposal of a new halobacterial genus Natrinema gen. nov., with two species Natrinema pellirubrum nom. nov. and Natrinema pallidum nom. nov. Int J Syst Bacteriol 48, 1187-1196.

Montalvo-Rodríguez, R., López-Garriga, J., Vreeland, R. H., Oren, A., Ventosa, A. \& Kamekura, M. (2000). Haloterrigena thermotolerans sp. nov., a halophilic archaeon from Puerto Rico. Int J Syst Evol Microbiol 50, 1065-1071.

Oren, A. \& Ventosa, A. (2002). International Committee on Systematics of Prokaryotes. Subcommittee on the taxonomy of Halobacteriaceae. Int J Syst Evol Microbiol 52, 289-290.

Oren, A., Ventosa, A. \& Grant, W. D. (1997). Proposed minimal standards for description of new taxa in the order Halobacteriales. Int J Syst Bacteriol 47, 233-238.

Purdy, K. J., Cresswell-Maynard, T. D., Nedwell, D. B., McGenity, T. J., Grant, W. D., Timmis, K. N. \& Embley, T. M. (2004). Isolation of haloarchaea that grow at low salinities. Environ Microbiol 6, 591-595.

Roh, S. W., Nam, Y.-D., Chang, H.-W., Kim, K.-H., Lee, H.-J., Oh, H.-M. \& Bae, J.-W. (2007a). Natronococcus jeotgali sp. nov., a halophilic archaeon isolated from shrimp jeotgal, a traditional fermented seafood from Korea. Int J Syst Evol Microbiol 57, 2129-2131.

Roh, S. W., Nam, Y. D., Chang, H. W., Sung, Y., Kim, K. H., Oh, H. M. \& Bae, J. W. (2007b). Halalkalicoccus jeotgali sp. nov., a halophilic archaeon from shrimp jeotgal, a traditional Korean fermented seafood. Int J Syst Evol Microbiol 57, 2296-2298.

Roh, S. W., Sung, Y., Nam, Y. D., Chang, H. W., Kim, K. H., Yoon, J. H., Jeon, C. O., Oh, H. M. \& Bae, J. W. (2008). Arthrobacter soli sp. nov., a novel bacterium isolated from wastewater reservoir sediment. J Microbiol 46, 40-44.

Romano, I., Poli, A., Finore, I., Huertas, F. J., Gambacorta, A., Pelliccione, S., Nicolaus, G., Lama, L. \& Nicolaus, B. (2007). Haloterrigena hispanica sp. nov., an extremely halophilic archaeon from Fuente de Piedra, southern Spain. Int J Syst Evol Microbiol 57, 1499-1503.

Rzhetsky, A. \& Nei, M. (1992). A simple method for estimating and testing minimum-evolution trees. Mol Biol Evol 9, 945-967.

Saitou, N. \& Nei, M. (1987). The neighbor-joining method: a new method for reconstructing phylogenetic trees. Mol Biol Evol 4, 406-425.

Sambrook, J., Fritsch, E. F. \& Maniatis, T. (1989). Molecular Cloning: a Laboratory Manual, 2nd edn. Cold Spring Harbor, NY: Cold Spring Harbor Laboratory.

Sehgal, S. N. \& Gibbons, N. E. (1960). Effect of some metal ions on the growth of Halobacterium cutirubrum. Can J Microbiol 6, 165-169. 
Tamura, K., Dudley, J., Nei, M. \& Kumar, S. (2007). MEGA4: Molecular Evolutionary Genetics Analysis (MEGA) software version 4.0. Mol Biol Evol 24, 1596-1599.

Tapingkae, W., Tanasupawat, S., Itoh, T., Parkin, K. L., Benjakul, S., Visessanguan, W. \& Valyasevi, R. (2008). Natrinema gari sp. nov., a halophilic archaeon isolated from fish sauce in Thailand. Int $J$ Syst Evol Microbiol 58, 2378-2383.

Tindall, B. J. (1990). Lipid composition of Halobacterium lacusprofundi. FEMS Microbiol Lett 66, 199-202.

Ventosa, A., Gutiérrez, M. C., Kamekura, M. \& Dyall-Smith, M. L. (1999). Proposal to transfer Halococcus turkmenicus, Halobacterium trapanicum JCM 9743 and strain GSL-11 to Haloterrigena turkmenica gen. nov., comb. nov. Int J Syst Bacteriol 49, 131-136.

Wayne, L. G., Brenner, D. J., Colwell, R. R., Grimont, P. A. D., Kandler, O., Krichevsky, M. I., Moore, L. H., Moore, W. E. C., Murray, R. G. E. \& other authors (1987). International Committee on Systematic Bacteriology. Report of the ad hoc committee on reconciliation of approaches to bacterial systematics. Int J Syst Bacteriol 37, 463-464.

Xin, H., Itoh, T., Zhou, P., Suzuki, K., Kamekura, M. \& Nakase, T. (2000). Natrinema versiforme sp. nov., an extremely halophilic archaeon from Aibi salt lake, Xinjiang, China. Int J Syst Evol Microbiol 50, 1297-1303.
Xu, X. W., Liu, S. J., Tohty, D., Oren, A., Wu, M. \& Zhou, P. J. (2005a). Haloterrigena saccharevitans sp. nov., an extremely halophilic archaeon from Xin-Jiang, China. Int J Syst Evol Microbiol 55, 25392542.

Xu, X. W., Ren, P. G., Liu, S. J., Wu, M. \& Zhou, P. J. (2005b). Natrinema altunense sp. nov., an extremely halophilic archaeon isolated from a salt lake in Altun Mountain in Xinjiang, China. Int J Syst Evol Microbiol 55, 1311-1314.

Yoon, J. H., Kang, S. S., Lee, K. C., Kho, Y. H., Choi, S. H., Kang, K. H. \& Park, Y. H. (2001). Bacillus jeotgali sp. nov., isolated from jeotgal, Korean traditional fermented seafood. Int J Syst Evol Microbiol 51, 1087-1092.

Yoon, J. H., Kang, K. H. \& Park, Y. H. (2003a). Psychrobacter jeotgali sp. nov., isolated from jeotgal, a traditional Korean fermented seafood. Int J Syst Evol Microbiol 53, 449-454.

Yoon, J. H., Lee, K. C., Weiss, N., Kang, K. H. \& Park, Y. H. (2003b). Jeotgalicoccus halotolerans gen. nov., sp. nov. and Jeotgalicoccus psychrophilus sp. nov., isolated from the traditional Korean fermented seafood jeotgal. Int J Syst Evol Microbiol 53, 595-602.

Yoon, J. H., Jung, S. Y., Kim, W., Nam, S. W. \& Oh, T. K. (2006). Nesterenkonia jeotgali sp. nov., isolated from jeotgal, a traditional Korean fermented seafood. Int J Syst Evol Microbiol 56, 2587-2592. 